\title{
The Relationship Between Serum Levels Of CA- 125 and Interleukin -6 with the Degree of Differentiation in Ovarian Neoplasms.
}

\author{
Minakshi Rajput ${ }^{1 *}$, C.V. Kulkarni ${ }^{1}$, Ashok Yadav $^{1}$, Sachin Sharma ${ }^{1}$ and Vinod Dhakad ${ }^{2}$ \\ ${ }^{1}$ Department of pathology Mahatma Gandhi Memorial Medical college, Indore(M.P.),INDIA \\ ${ }^{2}$ Department of Medicine Gajara raja Medical college, Gwalior(M.P.), INDIA
}

\begin{abstract}
Background: To study the serological correlation between serum levels of CA -125 and IL-6 with various histo morphological features of ovarian neoplasm.

Methods: Prospective study of two year duration from 2016 to 2018.Total of 40 women presented clinically with pelvic mass lesion were included. These patients undergoing concomitant serological analysis of CA -125 and IL-6. In each case, age, parity, marital life, radiological finding, histological type, degree of differentiation, extra ovarian tissues involvement was determined.

Result: Most of the ovarian neoplasm belongs to benign category 19/40 (47.5\%) then malignant tumors 15/40 (37.5\%). Surface epithelial tumours $(80 \%)$ were common histopathological findings with raised CA-125 and Interleukin-6 levels. Most of the patient present with abdominal pain in their late reproductive age group (41-60 years). There is significant correlation ( $p$-value $=.000)$ in rise of levels of CA125 and Interleukin-6 levels in patients with benign and malignant ovarian lesion. Levels of both the biomarkers are near normal levels in benign cases and levels were raised in malignant cases.

Conclusion: Amongst the ovarian neoplasm benign tumor were more common than malignant with predominance histological type is surface epithelial tumors. Serum levels of CA -125 and IL-6 were associated with histological grade in primary ovarian neoplasms, especially in high-grade malignant tumors, suggesting that high serological levels of these biomarkers are associated with lesions of more aggressive biological behavior.
\end{abstract}

Keywords: Ovarian Neoplasm, CA-125, Interleukin-6.

\section{Introduction}

Ovarian pathology is the widest and most complex problems in modern gynecology mainly through ovarian tumours. ${ }^{[1]}$ Primary neoplasms of ovary comprise benign and malignant lesions, which may present superficial germinative epithelial -differentiation of the stromal sexual cord. It is the third most common site of primary malignancy in female genital tract after cervix and endometrium accounting for $30 \%$ of all cancers of female genital tract. ${ }^{[2]}$

Malignant ovarian tumors are responsible for approximately $6 \%$ of all cancers affecting women, and correspond to the seventh most frequent cause of death, for around $80 \%$ of the cases are diagnosed in advanced stages. ${ }^{[3,4]}$ Ovarian cancer has an unknown natural evolution, starting often insidiously, without specific symptoms; the diagnosis is put during a routine exam. It is associated with an overall mortality of $75 \%$, but can be cured in up to $90 \%$ of cases if diagnosed while still limited to the ovaries. Attempts to develop an effective screening strategy for ovarian cancer have utilized ultrasonography and serum tumor markers. ${ }^{[5]}$ Despite the new techniques in imaging and genetics, the diagnosis of ovarian tumours is primarily dependent upon histological examination.

\section{Serological Tumor Markers For Ovarian Cancer}

- CA125

- Carcinoembryonic antigen

- CA15-3

- $\quad$ TAG-72

- HMFG2 (Human milk fat globule)

- PLAP (Placental alkaline phosphatase)

- $\quad \mathrm{NB} 70 / \mathrm{K}$

- Urinary gonadotropin core fragment peptide

- OVX1

- CA19-9

- $\quad$ LASA (Lipid-associated sialic acid)

- Tissue peptide antigen

- IL-6 


Tumor Markers In Non Epithelial Ovarian Cancer
\begin{tabular}{|l|l|}
\hline TUMOR MARKERS & TUMOR TYPE \\
\hline fetoprotein (AFP) & Germ cell tumours \\
\hline $\begin{array}{l}\text { human -chorionic } \\
\text { gonadotropin (beta-HCG) } \\
\text { Placental alkaline } \\
\text { phosphatase (PALP) Lactate } \\
\text { dehydrogenase (LDH) }\end{array}$ & Dysgerminoma \\
\hline Estradiol & $\begin{array}{l}\text { Stromal tumours } \\
\text { (including granulosa cell } \\
\text { tumour) }\end{array}$ \\
\hline Inhibin & Granulosa cell tumours \\
\hline
\end{tabular}

CA-125: The CA- 125 also known as MUC16 (sialomucin), is a glycoprotein synthesized by ovarian superficial cells. It is considered as the gold standard in the disease progression or even in the early diagnosis and clinical management of patients with ovarian tumors with epithelial differentiation. Normal blood levels are usually less than $35 \mathrm{U} / \mathrm{ml}$.Its specificity seems to be low in benign tumours with or without epithelial differentiation and it' s concentration is elevated in malignant tumors, principally in large lesions and/or advanced stages of the disease. More than $90 \%$ of women have high levels of antigen CA-125 when the cancer is advanced.

Interleukin -6: Interleukin-6 (IL-6) is a classic proinflammatory cytokine associated with a variety of pathological conditions, including cancer. Evidence supports the role of IL-6 in the pathophysiology of epithelial ovarian cancer (EOC) where the presence of an immunosuppressive network protecting tumor from immune system is also involved in EOC growth and progression. ${ }^{[6,7,8]} \mathrm{IL}-6$ is produced by ovarian cancer cells and can be isolated from the ascitic fluid and serum of patients and it's higher levels have been found in patients with ovarian cancer, which have been shown to correlate with the extent of the disease and poor clinical outcome. $[12,13,14,15]$

\section{Materials and Methods}

This prospective study of two year duration from 2016 to 2018 has been conducted in pathology department of Mahatma Gandhi Medical College and Maharaja Yeshwantrao Hospital, a tertiary care hospital of, Indore (M.P).Total of 40 women presented clinically with pelvic mass lesion probable of ovarian origin (Radio logically suggested) in the age group range from 11 years to 70 years were included. Patient with pelvic mass lesion of other than ovarian origin and already diagnosed cases of ovarian diseases were excluded. These patients undergoing concomitant serological analysis of CA -125 and IL-6. In each case, age, parity, marital life, radiological finding, histological type, degree of differentiation, extra ovarian tissues involvement was determined.

\section{Result}

Most of the ovarian neoplasm belongs to benign category $19 / 40(47.5 \%)$ followed by malignant tumors $15 / 40$ (37.5\%). Borderline tumors comprising of $7.5 \%$. Surface epithelial tumours $(80 \%)$ were common histopathological findings with raised CA-125 and Interleukin-6 levels. Most of the patient present with abdominal pain in their late reproductive age group(41-60 years). There is significant correlation ( $\mathrm{p}$-value $=.000$ ) in rise of levels of CA-125 and Interleukin-6 levels in patients with benign and malignant ovarian lesion. Levels of both the biomarkers are near normal levels in benign cases and levels were raised in malignant cases.

Table 1: Out of 40 neoplastic lesions 32 are surface epithelial tumours $(80 \%), 04$ cases of germ cell tumours $(10 \%)$ and 01 cases of sex cord stromal tumour $(7.5 \%)$ and 03 case in another category.

Most of the patients were of late reproductive age group i.e. 41 to 50 years of age $(32.5 \%)$ followed by premenopausal age group (27.5\%). Malignant tumours were more common in menopausal age group of 41 to 60 years of age while benign tumours were more common in reproductive age group of 31 to 50 years of age.

Table 2: Serum CA- 125 levels greater $>35 \mathrm{U} / \mathrm{ml}$ found in $6(31 \%)$ benign cases and $13(86 \%)$ malignant cases and CA- 125 levels $>65 \mathrm{U} / \mathrm{ml} \mathrm{3(15 \% )}$ benign cases and $12(80 \%)$ malignant

Graph 1: showing significant correlation (p-value .000) of serum levels of CA- 125 and IL-6 in patient with benign lesion. Majority of patient with benign lesion have values of both serological markers near normal levels.

Graph 2: showing significant correlation (p- value .000) of serum levels of CA- 125 and IL-6 in patient with malignant lesion. Levels of both biomarkers are raised in malignancy but with higher levels of IL-6 than CA-125.

Table 3: Neoplastic lesions are more common in parous women having parity of three to four $(45.0 \%)$, followed by $(32.0 \%)$ of parity $1-2$, followed by (17.5\%) of parity $>5$ of tumors are found in grand multipara.

\section{Discussion}

At present there are advancements made in the fields of cancer screening and diagnosis but carcinoma of ovary remains the leading cause of mortality. In present study 40 cases were studied, includes 03 cases $(7.5 \%)$ were 
Table 1: Histological type of Neoplastic Lesions

\begin{tabular}{|c|c|c|}
\hline Histological Type & Number of Cases & Percentage \\
\hline Surface Epithelial Tumours & 32 & $80 \%$ \\
\hline Sex Cord Stromal Tumours & 01 & $2.5 \%$ \\
\hline Germ Cell Tumours & 04 & $10 \%$ \\
\hline Others & 03 & $7.5 \%$ \\
\hline
\end{tabular}

Table 2: CA- 125, IL-6 Levels and Histo Pathological Findings

\begin{tabular}{|c|c|c|c|c|}
\hline \multirow{2}{*}{$\begin{array}{c}\text { Histopathological } \\
\text { Type }\end{array}$} & \multicolumn{2}{|c|}{ CA-125 ( U/ml) } & \multicolumn{2}{|c|}{ IL-6 ( Pg /ml) } \\
\hline & $<35$ & $>35$ & $<(0-15)$ & $>(0-15)$ \\
\hline Benign & 13 & 06 & 04 & 15 \\
\hline Borderline & 00 & 03 & 00 & 03 \\
\hline Malignant & 02 & 13 & 00 & 15 \\
\hline Others & 03 & 00 & 03 & 00 \\
\hline
\end{tabular}

Table 3: CA -125 and IL-6 Levels in Different Subtype

\begin{tabular}{|c|c|c|c|c|}
\hline \multirow{2}{*}{ Histological Subtype } & \multicolumn{2}{|c|}{ CA-125 (U/MI) } & \multicolumn{2}{c|}{ IL-6(Pg/MI) } \\
\cline { 2 - 5 } & $<35$ & $>35$ & 00 & $>(0-15)$ \\
\hline Surface Epithelial & 12 & 20 & 00 & 32 \\
\hline $\begin{array}{c}\text { Sex Cord Stromal } \\
\text { Tumour }\end{array}$ & 00 & 01 & 04 & 01 \\
\hline Germ Cell Tumour & 04 & 00 & 03 & 00 \\
\hline Other & 03 & 00 & 00 \\
\hline
\end{tabular}

Table 4: Based On Degree of Differentiation of Malignant Lesion

\begin{tabular}{|c|c|c|c|c|}
\hline \multirow{2}{*}{ Variables } & \multicolumn{2}{|c|}{ Serum levels of CA -125 } & \multicolumn{2}{c|}{ Serum levels of IL-6 } \\
\cline { 2 - 5 } & $<\mathbf{3 5} \mathrm{U} / \mathbf{m l}$ & $\mathbf{3 5} \mathbf{~ U / m l}$ & 00 & 03 \\
\hline Well differentiated & 02 & 01 & 00 & 02 \\
\hline $\begin{array}{c}\text { Moderately } \\
\text { differentiated }\end{array}$ & 00 & 02 & & \\
\hline Poorly differentiated & 00 & 10 & 00 & 10 \\
\hline
\end{tabular}

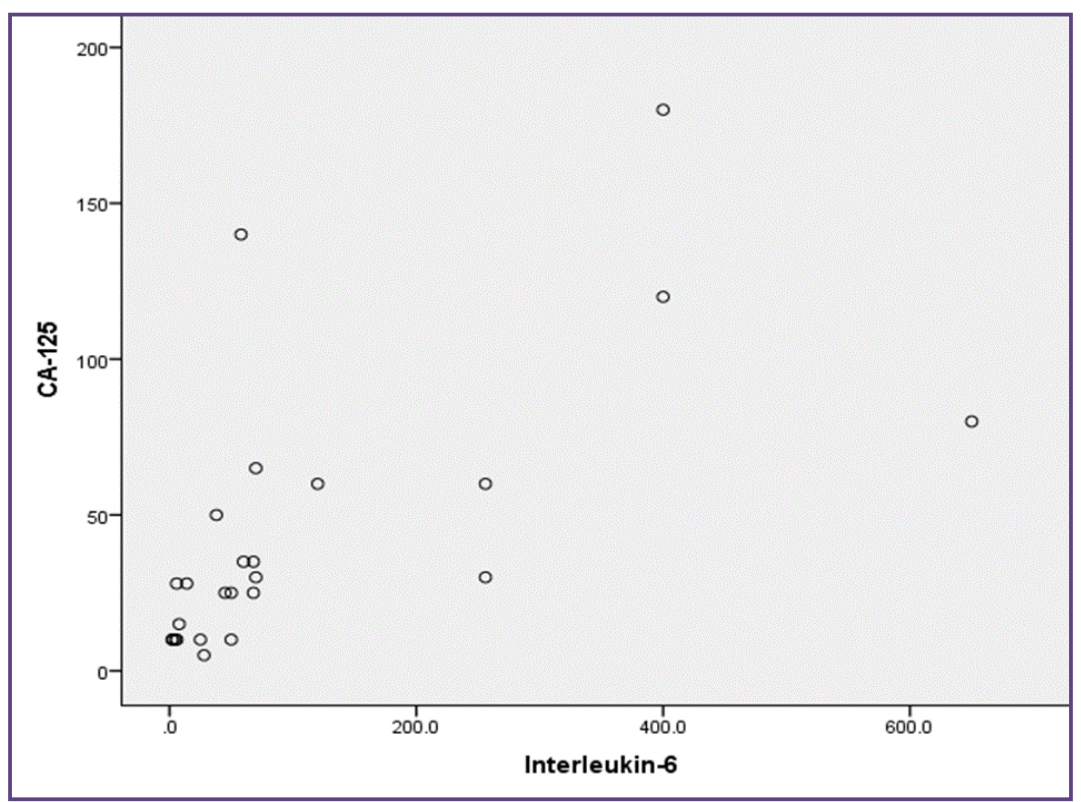

Graph 1: Correlation of CA- 125 and IL-6 Levels For Benign Lesion

Annals of Pathology and Laboratory Medicine, Vol. 6, Issue 7, July, 2019 


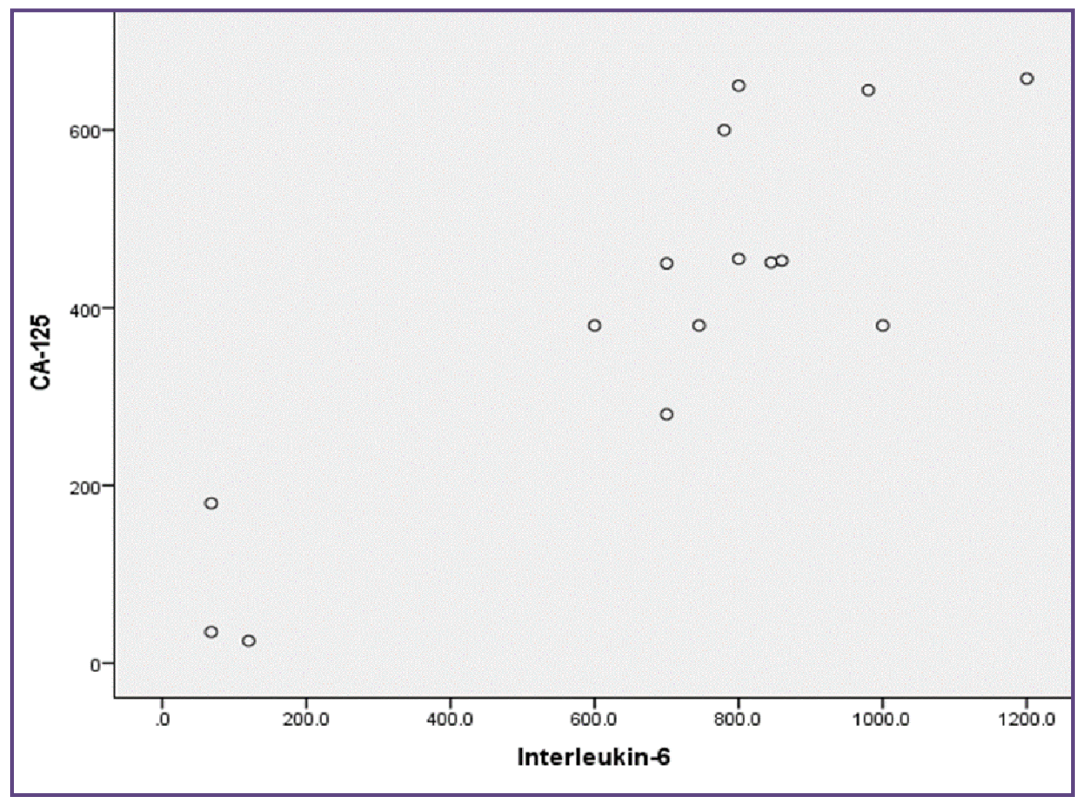

Graph 2: Correlation of CA- 125 and IL-6 Levels For Mlignant Lesion

non neoplastic lesion and 37 cases (92\%) were found to be neoplastic. Of these neoplastic lesions 19 cases were benign $47.5 \%$. Three cases $7.5 \%$ were borderline and 15 were malignant tumours $37.5 \%$ were recorded. Study done by Gupta $\mathrm{N}$ et $\mathrm{Al}$ showed $72.9 \%$ benign, $4.1 \%$ borderline and $22.9 \%$ were malignant. Study done by Vidhi et al ${ }^{[16]}$ showed $66 \%$ benign and $34 \%$ malignant tumours. Pilli et al ${ }^{[17]}$ had approximately similar results which showed that $75.2 \%$ ovarian tumours were benign, however this figure was only $59.2 \%$ in study carried in Pakistan by Ahmad et al. ${ }^{[18]}$

Swami GC et al observed commonest histological pattern was epithelial tumor $(61.6 \%)$. Kooning et al found that epithelial tumours represent $60 \%$ of all ovarian neoplasm and $85 \%$ of malignant ovarian neoplasm. ${ }^{[19]}$ Bushra et al also reported $96 \%$ epithelial tumours in her series. ${ }^{[20]}$ Vidhi et $\mathrm{al}^{[16]}$ found $73.58 \%$ epithelial tumours were diagnosed with 52 cases of malignant epithelial tumours accounting for $72.22 \%$ of all malignant neoplasms. R Jha \& s Karki ${ }^{[21]}$ found surface epithelial tumours constituting $52 \%$ of all tumours followed by germ cell tumours (42\%). In our study surface epithelial tumours constitute $80 \%$ of tumours followed by germ cell tumour (10\%).

Borderline ovarian tumours are of low malignant potential having favourable prognosis and relatively early age at onset. ${ }^{[22]}$ They comprise $4 \%-14 \%$ of all epithelial ovarian neoplasms. ${ }^{[23]}$ We diagnosed total 03 borderline malignancies $(7.5 \%)$, all 03 borderline cases in cases of borderline mucinous cystadenocarcinoma in 29 and 64 year old females and one borderline serous cystadenocarcinoma in a 36 year female.

Of all the germ cell tumours, only mature teratoma is benign and is the most common lesion in this group. ${ }^{[24]}$ This is consistent with our findings.

Sex-cord stromal tumours constitute about $2.5 \%$ of ovarian neoplasms. These tumours bring extra interest because of their hormonal effects which are rare in other ovarian neoplasms. Granulosa cell tumour is the most common malignant sex-cord stromal tumour as well as the most common estrogen-producing ovarian tumour. Adult granulosa cell tumours are far more common than the juvenile type. They occur predominantly in peri- and postmenopausal women. ${ }^{[25]}$ This is comparable to our findings as we found 01 case of granulosa cell tumour.

Peak incidence of ovarian tumour is between 21-50 years. ${ }^{[17]}$ Benign ovarian tumours occur in all age group whereas malignant ovarian tumours are more common in elderly, ${ }^{[26]}$ Majority of benign serous tumours occur in 4th-6th decade although they may occur in patients younger than 20 or older than 80 years. Serous carcinomas are extremely rare in first two decades of life, average patient age for serous carcinomas is 56 years. Mucinous cystadenoma may occur at any age but are most often diagnosed in 4th-6th decade. Mucinous cancers have mean age of 53-54 yrs. We also found nearly similar results.

Maximum of the patient with malignancy were over 45 years $32.5 \%$ which is comparable to study done by Chakrabortti and Lee. ${ }^{[27]}$ 
Nulliparity is considered to be a risk factor for the development of ovarian carcinoma. Most of the western studies have shown that nulliparous women have high incidence of ovarian cancers. According to these studies multiparity was associated with a significant reduction in risk of ovarian cancer and the high risk of ovarian cancer is inversely related to the number of full-term pregnancies and each additional sibling as associated with a risk reduction. ${ }^{[28-31]}$ However, the majority of our patients of ovarian tumours were having children $(87 \%)$ and a lesser number of patients turned out to be nulliparous (13\%). Of 31 patients suffering from ovarian carcinoma $19(61 \%)$ had a parity of $1-4,07$ patients $(23 \%)$ had a parity of 5 or more and $05(16 \%)$ were nullipara.

Ovarian tumours in the pediatric age group are not infrequent, Oumachigui et al, 1991. found the incidence to be six per cent of all ovarian tumours. Sawai and Sirsat recorded the incidence as $11.2 \%{ }^{6}$ (Sawai MM et al, 1973). present study show $5.4 \%$ in paediatric age group.

We found abdominal pain in $45 \%$ of cases as most common presenting complaint followed by abdominal distension in $32.5 \%$ and backache in $12.5 \%$. Gonsai et al found these findings in $52 \%$, and $16 \%$ cases respectively.

Kolwijck et al. describe that the pre-operative serum CA 125 levels are significantly higher in advanced lesions and in serous tumors. ${ }^{[32]}$

Osman et al. report that postoperative serum CA 125levels are associated with stage, histologic grade and survival in cases of ovarian carcinoma. ${ }^{[33]}$

Berek et al.34 recently published data from 36 patients with epithelial ovarian cancer and concluded that IL-6 may be a useful tumor marker in this disease, because it correlated with tumor burden, clinical disease status, and survival time.

\section{Conclusion}

Amongst the ovarian neoplasm benign tumor were more common then malignant with predominance histological type is surface epithelial tumors. Serum levels of CA -125 and IL-6 were associated with histological grade in primary ovarian neoplasms, especially in high-grade malignant tumors, suggesting that high serological levels of these biomarkers are associated with lesions of more aggressive biological behavior. It helps in effective therapeutic management of ovarian malignant tumours. An accurate diagnosis of ovarian malignancy by serological evaluation CA -125 and IL-6 and by histopathological diagnosis will help in rendering prompt and appropriate treatment to the patient.

\section{Reference}

1. Prof. Univ. Dr. Brăila M, Kamal K C, ClinicalEpidemiological, Imagistic, Histological And Immunohistochemical Study Of Ovarian Mucinous Tumours University Of Medicine And Pharmacy Craiova.

2. Adelmen S, Benson CD, Hertzler JH, surgical lesion of the ovary in infancy \& childhood, surggynecolobstate 1975, 141 : 219-222

3. Gupta N, Bisht D, Agrawal AK, Sharma UK, Comoarative study of ovarian cyst and tumour, J Pak Medical association December 2000,50(12);416-419.

4. Scully RE, Clement PB, Young RH, Miscellaneous primary tumours, secondary tumours, and non-neoplastic lesions of ovary. In : Mills SE, Carter D, Greenson JK, Oberman HA, Renter V, Stoler MH edts. Sternberg's diagnostic surgical pathology, 4th edn. Philadelphia : Lippincott Williams and Wilkins; 2004.p.2617

5. Zurawski VR, Jr, Orjaseter H, Andersen A, Jellum E. Elevated serum CA 125 levels prior to diagnosis of ovarian neoplasia: relevance for early detection of ovarian cancer. Int J Cancer. 1988;42:677-680. [PubMed]

6. Lidor YJ, Xu FJ, Martinez-Maza O, Olt GJ, Marks JR, Berchuck A, et al.Constitutive production of macrophage colony-stimulating factor and interleukin-6 by human ovarian surface epithelial cells. Exp Cell Res.1993;207(2):332-9. doi:10.1006/excr.1993.1200.

7. Watson JM, Berek JS, Martinez-Maza O. Growth inhibition of ovarian cancer cells induced by antisense IL-6 oligonucleotides. Gynecol Oncol.1993;49(1):8-15. doi:10.1006/gyno.1993.1077.

8. Lo CW, Chen MW, Hsiao M, Wang S, Chen CA, Hsiao SM, et al. IL-6 transsignaling in formation and progression of malignant ascites in ovarian cancer. Cancer Res. 2011;71(2):424-34. doi:10.1158/0008-5472.can-10-1496.

9. Friedman, EL, Hayes, DF, Kufe, DW. Reactivity of monoclonal antibody DF3 with a high molecular weight antigen expressed in human ovarian carcinomas. Cancer Res. 1986;46:5189-5194.

10. Bast, RC Jr, Knauf, S, Epenetos, A et al, Coordinate elevation of serum markers in ovarian cancer but not in benign disease. Hybridoma. 1987;6:228.

11. Gruhn JG. A selected historical survey pathology emphasizing neoplasms. In: Roth LM, Czernobilsky B (eds). Tumours and Tumour-like Conditions of the Ovary (Chapter 13). Churchill Livingstone: New York, 1985.

12. Graham H. Eternal Eve. The History of Gynaecology and Obstetrics. Doubleday and Company, Inc.: New York, 1951.

13. Pilli GS, Suneeta KP, Dhaded AV, Yenni VV. Ovarian tumours: a study of 282 cases. J Indian Med Assoc 2002; 100: 420, 423-4, 447.Morgagni GB. The Seats and Causes of Diseases (English Translation by Benjamin Alexander). Miller A, Cadell T and Johnson and Payne: London, 1769. 
14. Ahmad Z, Kayani N, Hasan SH, Muzaffar S, Gill MS. Histological pattern of ovarian neoplasm. J Pak Med Assoc 2000; 50: 416-9.

15. Oumachigui, Narasimhan KL, Reddy KS, et al. A clinicopathologic study of ovarian tumours in children. J Obstet Gynecol. 1991;140:441-5.

16. Pilli GS, Suneeta KP, Dhaded AV, Yenni VV. Ovarian tumours: a study of 282 cases. J Indian Med Assoc 2002; 100: 420, 423-4, 447.

17. Ahmad Z, Kayani N, Hasan SH, Muzaffar S, Gill MS. Histological pattern of ovarian neoplasm. J Pak Med Assoc 2000; 50: 416-9.

18. Rathi V et al Study Of Histopathological Spectrum Of Ovarian Lesions, Vikram University,Ujjain,2005.

19. Koonings PP, Campbell K, Mishell DR Jr, Grimes DA. Relative frequency of primary ovarian neoplasms: a10 year review. Obstet Gynaecol 1989; 74: 921-26

20. Rafiq B, Kokab H, Rao SI. Ovarian tumours. Professional Med J 2005;12(4):397-403.

21. R Jha\& S Karki , Nepal Medical College,Journal 2008:109(2)81-85.

22. Levi1 F, Vecchia CL, Randimbison L, Te VC. Borderline ovarian tumours in Vaud. Switzerland: incidence, survival and second neoplasms. Br J Cancer 1999;79(1):4-6

23. Burkholz KJ, Wood BP, Zuppan C. Best Cases from the AFIP: Borderline papillary serous tumour of the right ovary. Radiographics 2005;25:1689-92.

24. Outwater EK, Siegelman ES, Kim B, Chiowanich P, Blasbalg R, Kilger A. Ovarian Brenner tumours: MR imaging characteristics. Magn Reson Imaging 1998;16:1147-53

25. Herbst AL. The Epidemiology of Ovarian Carcinoma and the Current Status of Tumour Markers to Detect Disease. Am JObstet Gynecol 1994;170:1099-107.

26. Di Bonito L, Patriarca S, Delendi M, Alberico S. Ovarian tumours: anatomohistopathological contribution to their interpretation. Eur J Gynaecol Oncol 1988; 9: 324-30.

27. Chakrabortti DK, Lee CMS. Epidemiological study ovarian neoplasms. J Obstet gynaecol India 1990; 40:582 -6.

28. Greggi S, Parazzini F, Paratore MP, Chatenoud L, Legge F, Mancuso $\mathrm{S}$ et al. Risk factors for ovarian cancer in central Italy. Gynecol Oncol 2000; 79:50-4.

29. Salazar-Martinez E, Lazeano-Pance EC, Gonzalez Lira-Lira G, Escudero- De Los Rios P, Salmeron-Castro J, HernandezAvila M. Cancer Res 1999; 59:3658-62.

30. Yen ML, Yen BL, Bai CH, Lin RS. Risk factors for ovarian cancer in Taiwan: a case control study in a low incidence population. Gynecol Oncol 2003; 89: 318-24.

31. Zhang M, Lee AH, Binns CW. Reproductive and dietary risk factors for epithelial ovarian cancer in China. Gynecol Oncol 2004; 92: 320-6

32. KOLWIJICK, E. et al. Preoperative CA-125 level in 123 patients with borderline ovarian tumors: a retrospective analysis and review of the literature. Int J Gynecol Cancer, v. 19, n. 8 , p. 1335-8, 2009. [ Links ]

33. OSMAN, N. et al. Correlation of serum CA125 levels with stage, grade and survival of patients with epithelial ovarian cancer. J Clin Oncol, v. 25, n.18, suppl. 16006, 2007. [ Links ]

*Corresponding author:

Dr. Minakshi Rajput, Department of pathology Mahatma Gandhi Memorial Medical college, Indore(M.P.),INDIA

Phone: +91 9179190224

Email: minakshirajput79@gmail.com

Financial or other Competing Interests: None. 